\title{
A leitura literária na escola: ação e formação docente
}

\author{
Sheila Ferreira Gonçalo ${ }^{1}$, Ana Carolina Machado², Cícera Jéssica Paes \\ Casarin Monteiro², Lizandra Bianchi de Jesus², Manoela dos Santos Pereira ${ }^{2}$
}

\begin{abstract}
Resumo: Este relato de experiência discute as ações realizadas no âmbito do projeto de extensão "Leitura Literária na Escola: Ação e Formação Docente", desenvolvido no Instituto Federal de São Paulo - Campos do Jordão. O projeto teve como objetivo aprimorar a formação inicial de professores, aprofundando seus conhecimentos referentes à didática envolvida na prática pedagógica de leitura em voz alta de textos literários em sala de aula. Além disso, o projeto buscou estimular o prazer pela leitura, atendendo alunos dos anos iniciais do Ensino Fundamental. Foram planejadas e aplicadas situações de intervenção, envolvendo a leitura de livros de literatura infantil, seguida de uma atividade relacionada ao enredo da história lida. O planejamento das intervenções e a atuação em sala de aula possibilitaram às extensionistas a análise reflexiva sobre a efetividade das estratégias didáticas propostas, viabilizando uma investigação de caráter didático.
\end{abstract}

Palavras-chave: Leitura literária. Formação docente. Prática pedagógica.

Área Temática: Educação

\section{Literary Reading in the School: Action and Teacher Training}

\begin{abstract}
This report of experience discusses the actions carried out in the scope of the extension project "Literary Reading in the School: Action and Teacher Training", developed at the Federal Institute of São Paulo - Campos do Jordão. The project aimed to improve the initial formation of teachers, deepening their knowledge regarding the didactics involved in the pedagogical practice of reading aloud literary texts in the classroom. In addition, the project intended to stimulate reading pleasure by students in the early years of elementary school. Intervention situations were planned and applied, involving the reading aloud of children's literature books, followed by an activity related to the plot of the story read. The planning of the activities and the practice of a classroom lesson allowed the extensionists a reflection on the effectiveness of the didactic strategies, making feasible a didactic investigation.
\end{abstract}

Keywords: ELiterary Reading. Teacher training. Pedagogical practice.

\section{La lectura literaria en la escuela: acción y formación docente}

Resumen: EEste relato de experiencia discute las acciones realizadas en el marco del proyecto de extensión "Lectura Literaria en la Escuela: Acción y Formación Docente", desarrollado en el Instituto Federal de São Paulo - Cam-pos do Jordão. El proyecto tenía como objetivo mejorar la formación inicial de los docentes, profundizando sus conocimeientos en la practica pedagógica de leer en voz alta textos literarios en la aula. Además, el pro-yecto buscaba estimular el placer de la lectura en los estudiantes en los primeros años de la escuela primaria. Se han planificado y aplicado situaciones de intervención, involucrando la lectura de libros de literatura infantil, seguida de una actividad relacionada con la trama de la historia leída. La planifición de las inter-venciones y la actuación en la aula permitieron a las extensionistas el análisis reflexivo sobre la efectividad de las estrategias didácticas propuestas, viabilizando una investigación de carácter didático.

Palabras clave: Lectura literaria. Formación docente. Práctica pedagógica.

\footnotetext{
${ }^{1}$ Professora de Educação Básica, Técnica e Tecnológica do Instituto Federal de São Paulo (IFSP). Rua Monse-nhor José Vita, 280 - Abernéssia - Campos do Jordão/ SP, Telefone: (32) 3668-9620. E-mail: shei-la.goncalo@ifsp.edu.br.
}

${ }^{2}$ Aluna do Curso de Licenciatura em Pedagogia do Instituto Federal de São Paulo (IFSP). 


\section{INTRODUÇÃO}

A aproximação com a literatura deve iniciar desde a primeira infância, possibilitando à criança apreciar o contato com os livros e desenvolver o prazer em participar de situações em que a leitura esteja presente. Entretanto, nem sempre esse primeiro contato com o livro acontece precocemente no ambiente familiar. Torna-se, portanto, imprescindível que a escola planeje situações nas quais a leitura se apresente aos alunos de forma prazerosa. Nesse sentido, ler em voz alta textos de qualidade para os alunos, sem objetivar avaliá-los, é uma prática importante para incentivá-los a seguir no caminho da leitura. De acordo com Zilberman (2001) apud Formiga, Inácio e Barbosa (2015), a escola constitui o espaço por excelência de aprendizagem, valorização e consolidação da leitura, cooperando com o processo de legitimação da literatura e da escrita no mundo.

A leitura em sala de aula, principalmente a literária, portanto, traz inúmeros benefícios aos envolvidos, sendo crucial na formação do aluno leitor e crítico, além de se constituir como excelente aliada na sua alfabetização e letramento. Zilberman (2008) destaca que a leitura de textos literários é capaz de acionar a fantasia, possibilitando reflexões a respeito do cotidiano do leitor e incorporando novas experiências. Assim, de acordo com Abramovich (2009), "é através de uma história que se podem descobrir outros lugares, outros tempos, outros jeitos de agir e de ser, outra ética, outra ótica..." (p. 17).

Portanto, é necessário quebrar o paradigma da leitura apenas como instrumento de avaliação de desempenho escolar. A leitura inserida no cotidiano das escolas de forma burocrática, imposta como obrigação aos professores e alunos, a monotonia e a leitura apresentada apenas com um caráter avaliativo, podem refletir negativamente sobre o aluno, levando-o ao desinteresse. Assim, propor atividades e situações de leitura diferenciadas contribui para a construção do prazer pela leitura. É por meio da leitura em voz alta realizada pelo professor que é possível ao aluno o adentramento em um universo mágico (SÃO PAULO, 2007).

Assim, é necessário que o professor entenda que a atividade de leitura não pode ser considerada como um tempo para descansar ou para descontrair a turma, e sim como um momento planejado na rotina da sala de aula, considerando "o aluno como um participante ativo no levantamento de hipóteses e na escolha de estratégias para construir sentidos" (SANTOS, 2014, p.22).

É equivocado pensar que as situações didáticas envolvendo a leitura constituem, necessariamente, o aluno com o livro em mãos, decodificando o que nele está escrito. Há uma grande disparidade entre o ler de fato e a decodificação de letras. Ser leitor não é apenas saber decodificar, é conseguir ir além do texto. De acordo com Santos (2014), forma-se um leitor quando o aluno tem o poder de fazer inferências sobre um texto, ler nas entrelinhas e perceber sua estrutura. Em contrapartida, de acordo com Silva (1988) apud Santos (2014), o aluno "ledor" limita-se apenas àquilo que é apresentado de forma explícita no texto. Assim, as situações de leitura compartilhadas entre o professor (leitor maduro) e os alunos (leitores principiantes) apresentam-se como uma prática pedagógica de suma importância no decorrer de toda a trajetória escolar. Como afirma Ferreiro (2002), 
Há crianças que ingressam no mundo da linguagem escrita através da magia da leitura e outras que ingressam através do treino das tais habilidades básicas. Em geral, os primeiros se convertem em leitores, enquanto os outros costumam ter um destino incerto (FERREIRO, 2002, p.59).

Entretanto, infelizmente, a leitura de textos literários nas escolas brasileiras ainda se apresenta como algo burocrático e descontextualizado, e a literatura como um bem cultural distante da realidade dos alunos, principalmente nas instituições destinadas ao atendimento das camadas populares (ZILBERMAN, 2009). A falta de conexão entre os livros de literatura e os contextos educacionais dificulta muito o processo de formação de leitores assíduos e competentes, pois é somente através da participação permanente em situações em que a leitura se coloca como uma prática geradora de prazer e de identidade que se desenvolve nos indivíduos o interesse pela leitura, visto que

\footnotetext{
é pela frequência que os alunos aprenderão a ler contos (mesmo que por meio de leitura do professor), conhecerão as regularidades desses textos e aprenderão a lidar com as dificuldades que a leitura muitas vezes coloca (SÃO PAULO, 2007, p.45).
}

Cabe também salientar a importância da escolha de livros que possuam qualidade literária e editorial. Nesse sentido, pensar em qualidade envolve, primeiramente, não subestimar a capacidade de entendimento dos alunos, pois optar por histórias de fácil entendimento e de má qualidade, que não possuem um bom enredo, redigidas com linguagem empobrecida ou que não sejam escritas de forma interessante, impossibilita ao aluno o acesso a um vocabulário mais rico, limitando as suas possibilidades linguísticas (SÃOPAULO, 2007). Ao contrário, a escolha de materiais literários de boa qualidade coloca a literatura como uma grande aliada no processo de aprendizagem, pois, além de dar acesso a um vocabulário mais rico e de qualidade estética, se constitui como uma possibilidade de se pensar o ser e estar no mundo, levando os leitores a repensá-lo (SANTOS 2014).

\section{OBJETIVOS}

O projeto teve como objetivo aprimorar a formação inicial de professores, aprofundando seus conhecimentos referentes à didática envolvida na prática pedagógica de leitura em voz alta de textos literários em sala de aula. Além disso, o projeto buscou estimular o prazer pela leitura, atendendo alunos dos anos iniciais do Ensino Fundamental.

\section{METODOLOGIA}

O projeto foi apoiado pela Coordenadoria de Extensão do Instituto Federal de São Paulo do campus Campos do Jordão e teve duração de 4 meses. Para o desenvolvimento do projeto estabeleceu-se uma parceria com uma escola municipal de Campos do Jordão que atende as séries iniciais do Ensino Fundamental. O projeto contou com a participação de quatro extensionistas, alunas do curso de licenciatura em pedagogia, e quatro turmas foram contempladas, sendo duas de $1^{\circ}$ ano e duas de $2^{\circ}$ ano (totalizando 108 alunos atendidos). Desse 
modo, cada uma das alunas ficou responsável por uma sala, atuando de maneira intercalada, entre dias de observação da aula e dias de leitura, esta sempre seguida por uma atividade lúdica.

No decorrer do projeto, as extensionistas reuniam-se semanalmente com a orientadora do projeto para discutir as situações vivenciadas e planejar as próximas leituras. No início do processo, foi realizada a seleção dos livros pelas quatro extensionistas e a professora orientadora, sempre prezando pela qualidade do livro a ser lido. Desse modo, cada uma das extensionistas ficou responsável por elaborar o planejamento da leitura dos livros que escolheu e da atividade a ser desenvolvida, considerando a faixa etária dos alunos atendidos, enquanto as demais participantes do projeto colaboraram com sugestões.

As situações planejadas foram discutidas antecipadamente com as professoras regentes de cada turma que contribuíam também com sugestões. As leituras foram realizadas semanalmente, sendo os resultados analisados por meio da elaboração de relatos reflexivos que eram posteriormente discutidos coletivamente entre as extensionistas e a docente orientadora do projeto.

\section{RESULTADOS E DISCUSSÃO}

Durante as duas primeiras semanas do projeto, as alunas extensionistas observaram o cotidiano da sala de aula. Neste período, foi possível verificar que a prática da leitura pelo professor já estava presente nas turmas que participaram do projeto. Presenciou-se a leitura feita pelas professoras, geralmente de contos clássicos, seguida por atividades envolvendo sequencialidade e reconto da história lida. Com relação ao trabalho desenvolvido com contos de fadas, Rezende (2018) observou que, até o $5^{\circ}$ ano do Ensino Fundamental, esse gênero literário, juntamente com as fábulas, é considerado como mais próximo da experiência infantil, sendo exercitado durante esse período escolar principalmente por meio de exercícios de reprodução de modelos desse tipo de narrativa.

Dessa maneira, buscando contribuir com a formação leitora dos alunos, buscou-se desenvolver as propostas utilizando livros com temas e estilos diversificados e propostas de atividades com caráter lúdico nas quais os alunos pudessem ser protagonistas.

Salvo a primeira leitura, que foi planejada pela docente orientadora do projeto, a seleção dos livros que seriam utilizados foi feita em conjunto com todas as alunas extensionistas, a partir de um acervo proposto pela orientadora. Após as escolhas, ficou a cargo das extensionistas a elaboração da situação de leitura e da atividade para seus respectivos livros.

$\mathrm{Na}$ fase do planejamento, foi necessário pensar em estratégias que pudessem despertar o interesse dos alunos, considerando que o desenvolvimento da atividade ocorreria em quatro diferentes turmas (cada qual com a atuação de uma extensionista). Os recursos necessários deveriam ser pensados, bem como o tempo disponível para a realização. Assim, as propostas foram desenvolvidas de modo que estimulassem a criatividade e oralidade das crianças, e promovessem o encantamento pela leitura. 
Todas as alunas extensionistas tiveram a oportunidade de planejar duas intervenções, a partir dos livros previamente selecionados. No decorrer do projeto, foi possível perceber a importância do planejamento das situações didáticas, visto que ter os objetivos claros, assim como prever possíveis intercorrências, favorece o desenvolvimento da atividade proposta e, consequentemente, da aprendizagem. Neitzel, Bridon e Weiss (2016) apontam que a mediação adequada de leitura por parte do professor, além do acesso ao mundo da leitura, possibilita também subverter o texto lido/ouvido e utilizá-lo como entrada para outros textos, ampliando a aprendizagem dos alunos.

Foi possível perceber que a constância e a frequência são grandes aliadas na leitura em sala de aula. Foi possível verificar também que a prática de retomar os combinados e a realização da leitura em voz alta, como uma atividade permanente semanal, colaborou para a melhora do envolvimento das turmas durante o projeto.

As situações planejadas envolveram alguns procedimentos didáticos que objetivaram a qualidade das propostas. Para iniciar a leitura, as alunas extensionistas declamavam um versinho que a cada semana remetia a algum aspecto do enredo do livro que seria lido. Posteriormente, realizavam a leitura do título, dos nomes dos autores e ilustradores e da editora do livro, seguida da exploração das imagens da capa. Nesse momento, os alunos eram incentivados a antecipar o enredo, inferindo sobre as possíveis situações que seriam apresentadas pelo autor da obra.

Durante a leitura, procurou-se utilizar uma entonação especial de voz no sentido de dar vida às palavras escritas pelos autores. De maneira geral, as crianças demonstraram grande prazer em ouvir as histórias lidas. Nesse sentido, Oliveira (2010) aponta que a leitura em voz alta, quando realizada por um leitor fluente, é um dos caminhos possíveis para a experimentação literária engajada. Para a autora, o jogo de sonoridades aguça os sentidos daqueles que ouvem.

Após a finalização da leitura, os alunos foram convidados a desenvolver atividades diversificadas, de acordo com o livro lido. Essas propostas envolveram a elaboração de ilustrações, a produção escrita de um livro coletivo e de um livro individual, a produção de um autorretrato, cruzadinha, escrita com letras móveis, dinâmicas, quebra-cabeças e a escrita coletiva de uma carta.

Observou-se que os alunos se sentiam participantes do projeto, já que davam sugestões para os próximos livros e questionavam quais seriam as próximas atividades. Além disso, sentiam-se valorizados sempre que percebiam que as atividades, de fato, tiveram um propósito.

Durante todo o projeto, algumas dificuldades foram encontradas. Ficou latente que a falta de familiaridade com a prática de reger uma sala dificultou a atuação durante a leitura. Apesar de anos ocupando os bancos escolares, a realização do projeto colocou as alunas extensionistas em uma posição diferenciada frente à sala de aula. Manter o foco e a atenção dos alunos, explicitar o que deveria ser feito, como a atividade se daria e o esclarecimento de dúvidas foram ações que trouxeram grande dificuldade, impulsionando a busca por estratégias pedagógicas baseadas em conhecimentos teóricos. Nesse sentido, Barros e Gomes (2008) 
apontam para a importância de projetos que proporcionem ao professor experiências pessoais e pedagógicas com a leitura. Ao investigarem as relações entre professores e a leitura, os autores verificaram que a maioria dos professores que participaram da pesquisa não havia desenvolvido, ao longo da vida, uma relação afetiva com o ato de ler.

Além do momento do planejamento e da leitura propriamente dita, também serviram como instrumento formativo os registros pedagógicos elaborados pelas alunas extensionistas. A escrita desses registros foi fundamental para que as extensionistas tivessem a oportunidade de refletir sobre a própria atuação, considerando as consequências, positivas ou não, das ações que envolveram sua prática docente. Esses escritos proporcionaram a oportunidade de as alunas extensionistas assumirem um olhar de pesquisador da prática pedagógica, relacionando os conteúdos teóricos aprendidos no curso de pedagogia e a prática em situações reais em sala de aula.

\section{CONCLUSÕES}

O projeto contribuiu de maneira positiva para que as participantes pudessem ter seu primeiro contato com a sala de aula e com os alunos, de modo que percebessem não só a complexidade em lecionar e compreender as crianças, como também pensar na melhor maneira para lidar com elas, sempre as respeitando e cultivando dentro de cada uma delas a vontade de estar na escola.

Assim, a participação no projeto foi de suma importância para a formação docente, pois propiciou experiências em chão escolar, permitindo uma associação entre os conhecimentos teóricos adquiridos no curso de licenciatura em pedagogia e a prática de sala de aula. Além disso, possibilitou o conhecimento prático e teórico sobre a prática pedagógica da leitura em sala de aula, prática essa capaz de auxiliar na formação do indivíduo leitor e crítico, que consegue ir além daquilo que lhe é oferecido, de enxergar as reais intenções do autor do texto e de fazer inferências. Talvez aqui se constitua também a maior contribuição para os alunos atendidos no projeto, pois é desde cedo que se deve suscitar no aluno o interesse pela leitura, para que no futuro, possam tornar-se verdadeiros leitores e tenham um olhar crítico sobre as situações.

Nesse sentido, o projeto foi riquíssimo, proporcionando erros e acertos, reflexões, troca de saberes, criação e fortalecimento de laços. Disseminou o prazer pela leitura nos alunos, prazer esse que vingará no futuro, se constituindo como um passo para a formação de alunos leitores e críticos.

\section{REFERÊNCIAS}

ABRAMOVICH, Fanny. Literatura Infantil: Gostosuras e Bobices. São Paulo: Scipione, 2009.

BARROS, Tristana Nascimento e GOMES, Erissandra. O perfil dos professores das séries iniciais e a prática de leitura em sala de aula, Revista CEFAC, São Paulo, v. 10, n. 3, p. 332-342, 2008.

FERREIRO, Emília. Passado e presente dos verbos ler e escrever, São Paulo: Cortez, 2002. 
FORMIGA, Girlene Marques; INÁCIO, Francilda Araújo; BARBOSA, Socorro de Fátima Pacífico. Literatura, escola e formação literária: entre práticas e descaminhos, Revista Principia, João Pessoa/, n. 28, p. 169-177, 2015.

NEITZEL, Adair de Aguiar; BRIDON, Janete; WEISS, Cláudia Suéli. Mediações em leitura: encontros na sala de aula, Revista Brasileira de Estudos Pedagógicos, Brasília, v. 97, n. 246, p. 305-322, 2016.

OLIVEIRA, Eliana Kefalás. Leitura, voz e performance no ensino de literatura, Revista Signótica, Goiania, v. 22, n. 2, p. 277-307, 2010.

REZENDE, Neide Luzia de. Leitura e escrita literárias no âmbito escolar: situações e perspectivas, Revista Estudos Avançados, São Paulo, v. 32, n. 93, p. 93-105, 2018.

SANTOS, Leonor W. dos. Leitura literária na escola, Revista Interdisciplinar, Itabaiana, ano 9, v. 21, p. 21-33, 2014.

SÃO PAULO. Guia de planejamento e orientações didáticas para o professor do $2^{\circ}$ ano do Ciclo 1. São Paulo: Secretaria Municipal de Educação/ DOT, 2007.

ZILBERMAN, Regina. O papel da literatura na escola, Revista Via Atlântica, São Paulo, n. 14, p.11-22, 2008.

Submetido em: 30/05/2019 Aceito em: 12/09/2019. 